\title{
Transplantation of human umbilical cord mesenchymal stem cells to treat premature ovarian failure
}

Oldouz Shareghi-oskoue ${ }^{1,2}$, Leili Aghebati-Maleki ${ }^{3,4^{*}}$ and Mehdi Yousefi ${ }^{1,4^{*}}$

\begin{abstract}
As one of the problems and diseases for women before 40 years, premature ovarian failure (POF) could be characterized by amenorrhea, low estrogen levels, infertility, high gonadotropin levels, and lack of mature follicles. Causes of the disease involve some genetic disorders, autoimmunity diseases, and environmental factors. Various approaches have been employed to treat POF, however with limited success. Today, stem cells are used to treat POF, since they have the potential to self-repair and regenerate, and are effective in treating ovarian failure and infertility. As mesenchymal stem cell (MSC) could simultaneously activate several mechanisms, many researchers consider MSC transplantation to be the best and most effective approach in cell therapy. A good source for mesenchymal stem cells is human umbilical cord (HUCMSC). Animal models with cyclophosphamide are required for stem cell treatment and performance of HUCMSC transplantation. Stem cell therapy could indicate the levels of ovarian markers and folliclestimulating hormone receptor. It also increases ovarian weight, plasma E2 levels, and the amount of standard follicles. Herein, the causes of POF, effective treatment strategies, and the effect of HUCMSC transplantation for the treatment of premature ovarian failure are reviewed. Many studies have been conducted in this field, and the results have shown that stem cell treatment is an effective approach to treat infertility.
\end{abstract}

Keywords: Premature ovarian failure (POF), Human umbilical cord mesenchymal stem cell (HUCMSC), Stem cell transplantation

\section{Introduction}

Premature ovarian failure (POF) is one of the problems and diseases for women's reproductive health, the frequency of which has increased in recent years $[1,2]$. POF is among the leading causes of female infertility prior to 40 years of age [3-5] and is characterized by amenorrhea, low estrogen levels, infertility, high gonadotropin levels, and lack of mature follicles [6-9]. These patients often have abnormal karyotypes, low levels of

\footnotetext{
*Correspondence: aghebatil@tbzmed.ac.ir; Yousefime@tbzmed.ac.ir ${ }^{3}$ Immunology Research Center, Tabriz University of Medical Sciences, Tabriz, Iran

${ }^{4}$ Department of Immunology, School of Medicine, Faculty of Medicine, Tabriz University of Medical Sciences, Tabriz, Iran

Full list of author information is available at the end of the article
}

follicle-stimulating hormone, and decreased ovarian reserves $[10,11]$. Also, negative consequences of POF include an elevated risk of cardiovascular disease, osteoporosis, and sexual dysfunction $[12,13]$.

Ovarian follicles include 3 types of cells: granulosa cells, oocytes, and theca cells [13]. Granulosa cells and oocytes possess FSH and LH receptors [14, 15], which are required for the growth and development of follicles [13, $16,17]$.

Folliculogenesis is an organized and orderly process during which follicles grow, develop, and are prepared. Following these stages, ovulation occurs. This process changes during POF (Fig. 1) [18-21]. There are two main types of POF. In the first one, there exist few to no residual follicles, the causes of which could include genetic original author(s) and the source, provide a link to the Creative Commons licence, and indicate if changes were made. The images or other third party material in this article are included in the article's Creative Commons licence, unless indicated otherwise in a credit line to the material. If material is not included in the article's Creative Commons licence and your intended use is not permitted by statutory regulation or exceeds the permitted use, you will need to obtain permission directly from the copyright holder. To view a copy of this licence, visit http://creativecommons.org/licenses/by/4.0/. The Creative Commons Public Domain Dedication waiver (http://creativeco mmons.org/publicdomain/zero/1.0/) applies to the data made available in this article, unless otherwise stated in a credit line to the data. 
disorders, chemotherapy, pelvic radiation, and surgery. In the second type, there are too many follicles, and its causes include autoimmune ovarian disease, which damage maturing follicles but leaves the primordial follicles intact $[13,22,23]$.

There is now evidence that some cases of this disease are due to misdiagnosis of the immune system in the ovaries [24]. Numerous evidences including endocrine disorders, histological and immunological features, transient estrogen deficiency, clinical reversibility, and manifestations of circulating ovarian antibodies in serum samples of POF-suffering women have suggested an immune source [24-27] ( Fig. 1).

\section{Etiology}

Folliculogenesis is a regular process [28], in which primary follicles develop into secondary follicles and then into antral follicles. Next, ovulation takes place. If this natural process changes, it will lead to POF $[28,29]$. POF causes are unidentified in $90 \%$ of cases; however, the number of known causes and genetic factors continue to increase (Table 1) [30].

\section{Genetic disorders}

Few cases of family POFs have been reported, and several genetic disorders have been demonstrated in POF patients, indicating an inherited genetic disorder[31, 32]. About $20-30 \%$ of women have POF, which indicates a common hereditary POF susceptibility [33]. POF may be a heterogeneous diseases caused by mutations in a number of genes. It has been shown that with each mutation, only a few cases of POF occur [34]. Several genetic disorders, including Turner syndrome, disorder in X chromosome, fragile $\mathrm{X}$ syndrome, and autosomal gene mutation, have been observed in POF cases [13, 35-46].

\section{X chromosome disorder}

Genetically, ovarian failure is linked to X chromosomal abnormalities. These anomalies may include a small defect in chromosomal arrangement such as deletion, isochromosomes, and X-chromosome-autosomal translocation that is balanced; however, complete elimination of a X (Turner syndrome) has also been reported [47]. Complete or almost complete absence of a X chromosome in humans leads to ovarian dysgenesis, characterized by primary amenorrhea, short stature, and distinct phenotypic features [48]. In the presence of only one $\mathrm{X}$ chromosome, the ovarian follicles. It is declining from birth. Histological data show that ovulation in these individuals continues naturally until diplotin oocytes. It begins to combine in the follicles.

The next block in full production The follicles appear as follicular atresia $[49,50]$.
Table 1 Etiology of premature ovarian failure

\begin{tabular}{|c|c|c|}
\hline POF causes & Example & References \\
\hline Genetic & $\begin{array}{l}\text { Turner syndrome } \\
\text { BMP15 } \\
\text { Mutation in LH and FSH receptors } \\
\text { Galactosemia and inhibin mutation } \\
\text { Mutation of FOXL2, PMM2, GDF9 } \\
{[31,32]}\end{array}$ & [33-59] \\
\hline Enzymatic & 17a-hydroxylase, aromatase & {$[60]$} \\
\hline Autoimmunity & $\begin{array}{l}\text { Associated diseases: } \\
\text { Addison's diseases } \\
\text { Vitiligo } \\
\text { Myasthenia gravis } \\
\text { Systemic lupus erythematosus } \\
\text { Celiac disease } \\
\text { Autoimmune polyglandular } \\
\text { syndrome } \\
\text { Ovarian autoantibody } \\
\text { Zona pellucida autoantibody } \\
\text { Immune cells imbalance: } \\
\text { Enhancement in CD4+T cell } \\
\text { and B cell }\end{array}$ & {$[61]$} \\
\hline Vaccination & HPV-vaccination & {$[62]$} \\
\hline $\begin{array}{l}\text { Chemotherapy And } \\
\text { radiation therapy }\end{array}$ & $\begin{array}{l}\text { Cyclophosphamide, } \\
\text { Nitrogen Mustard }\end{array}$ & [63] \\
\hline Environmental & Viral infections, smoking & {$[64,65]$} \\
\hline
\end{tabular}

POF premature ovarian failure, BMP15 bone morphogeneticprotein $15, \mathrm{LH}$ luteinizing hormone, FSH follicle-stimulating hormone, FOXL2 Forkhead box L2, PMM2 phosphomannomutase 2, GDF9 growth/differentiation factor 9

\section{Fragile $X$ pre-mutations}

About 20\% of women with fragile X pre-mutation will show symptom of fragile $\mathrm{X}$-associated primary ovarian insufficiency (FXPOI) [51, 52]. Fragile X syndrome is a triple repeated disease [53]. The complete mutation results in Fragile X Syndrome, a dynamic ternary replication located in the $5 \%$ untranslated region of the FMR1 gene [54]. Premature alleles have approximately 60 to 199 replications, are unstable, and are not considered harmful in principle [37]. That is, it does not appear to be the result of a long repetition device phenotype [54]. Preliminary findings suggest that undamaged heterozygotes are at risk for premature menopause and increased twinning rates, both of which are signs of ovarian failure [54, 55]. Women with fragile X chromosome have increased FSH and decreased inhibin $\mathrm{B}$ levels proposing ovarian aging [56].

\section{Autosomal disorder}

Galactosemia is a rare autosomal recessive disease caused by a deficiency of the enzyme galactose-1-phosphate uridyltransferase (GALT).The GALT gene is located on chromosome 9p13 57. Prevalence POF in female patients with galactosemia is $70-60 \%$. Due to the toxic effect of galactose (or one of the metabolites) on follicular 
structures, the initial number of oogonia decreases during fetal life, accelerating follicular atresia 58.

\section{Autoimmunity and POF}

Some POF cases may be due to recognizing your abnormality by the immune system [59]. The evidences for an autoimmune etiology are: (1) presence of lymphocytic oophoritis [60-62]. (2) Demonstration of ovarian autoantibodies [62]. (3) Associated autoimmune disorders [62]. Oophorite is primarily characterized by cellular penetration of macrophages, natural killer cells, $\mathrm{T}$ lymphocytes, plasma cells, and B lymphocytes. The target of lymphocyte infestation may be class II MHC on granulosa cells. Anti-ovarian antibodies have been reported in POF [61].

Several autoimmunity diseases can cause POF [4]. It has been reported that $20 \%$ of POF patients suffer from concomitant autoimmune diseases [63], including adrenal disease, thyroid complications, and diabetes mellitus [64]. Ovarian failure might be observed as a result of autoimmune polygon syndromes type I and II. Characterization of type I syndrome is determined by adrenal insufficiency, hypothyroidism, chronic cutaneous mucosal candidiasis, hypothyroidism, and POF. On the other hand, characterization of type II syndrome is determined by thyroid autoimmune disease, adrenal insufficiency, POF, and type 1 diabetes [30, 65]. POF-related autoimmune diseases are Vitiligo, Myasthenia gravis, Addison's disease, systemic lupus erythematosus, celiac disease, and autoimmune polygon syndrome $[4,13,62$, 66-68].

\section{Steroidogenic enzyme defect}

Defects in proteins and enzymes involved in the steroidation pathway, including $17 \alpha$-hydroxylase and aromatase deficiency, could cause POF [13, 69, 70]. Steroid-producing cells (hilar cells, granulosa cells, theca internal and corpus luteum) and autoantibodies to steroid-producing cells are widely present in POF associated with Addison's disease [71]. In autoimmune oophoritis, lymphatic infiltration is confined to secondary and antral follicles that have theca cells. This finding shows that steroid-producing cells express the antigens that stimulate the immune response [62]. Patients with enzyme deficiency other than 21-hydroxylase are very rare. In particular, a rare defect is 17,20-desmulase. Unlike other enzyme deficiencies that affect adrenal synthesis effects on corticosteroids and androgens, 17,20-desmulase inactivity affects only androgens and subsequent estrogen formation [72, 73]. Because of the activity of 17,20-desmulase and $17 \mathrm{a}$-hydroxylase in the adrenal cortex, the gonads are catalyzed by a polypeptide complex. However, there are some reports of specific defects in a enzymatic activity [74]. 17,20-Desmulase deficiency syndrome is a homozygous genetic disease [75]. 17a-hydroxylase is a rare enzyme associated with puberty, primary amenorrhea, hypogonadotropism, hypertension, and hypokalemia, which could also cause ovarian failure due to defects in ovarian follicular maturation and ovarian steroid synthesis [76].

\section{Vaccination}

Recently, POF was observed following HPV vaccination [77]. Responses of the autoimmune system to vaccines are a major aspect of autoimmune/inflammatory syndromes. HPV vaccination acts as helpers and results in POF $[13,78]$. The cause is unknown in $90 \%$ of cases. Many studies have reported premature ovarian failure as a possible side effect of vaccination [79].

\section{Chemotherapy and radiotherapy}

Among the most significant POF causes exist radiation therapy and chemotherapy used to treat cancer [80]. Although improving cancer with chemotherapy and radiotherapy in the young population leads to enhanced and durable survival [30], complications such as ovarian failure are possible. With increase in age after puberty, chemotherapy and radiation therapy could lead to POF [81]. As ovarian function is characterized by cells with rapid turnover, there is a potential similarity to tumor cells in that both are primary targets for chemotherapeutic agents. Ovarian primordial follicular cells have no ability to regenerate, and destruction of these cells leads to ovarian dysfunction which manifests as premature ovarian failure and infertility [82]. This type of treatment has several side effects, such as oocyte depletion with damage to DNA, and the disruption of functional and structural properties of oocytes [13, 81, 83, 84].

To solve this problem, in some studies to prevent premature ovarian failure due to chemotherapy (POF), temporary ovarian suppression with luteinizing hormone-releasing hormone (LHRHa) agonists has been used $[85,86]$.

\section{Environmental factors}

Several environmental factors, such as viral infections, smoking, could cause infertility and POF [13, 87-90]. Studies have shown that smoking can lead to premature ovarian failure [91, 92]. Cigarette smoke comprises toxic polycyclic hydrocarbons which are harmful to germ cells and reduce follicle aging [93]. Smoking is the most widely studied toxin that alters ovarian function, and on average, the female smokers experience menopause earlier than nonsmokers suggesting a possible detrimental effect of cigarette smoking on ovarian 
Table 2 Treatment strategies

\begin{tabular}{|c|c|c|}
\hline Treatment strategies & & References \\
\hline \multirow[t]{8}{*}{ Hormone replacement therapy } & $\begin{array}{l}\text { Estrogen replacement equivalents } \\
\text { Conjugated equine estrogens }\end{array}$ & {$[96,97]$} \\
\hline & Piperazine estrone sulfate & \\
\hline & Micronized 17P-estradiol & \\
\hline & $\begin{array}{l}\text { Transdermal estrogen path } \\
\text { Progestin replacement equivalents }\end{array}$ & \\
\hline & Medroxyprogesterone acetate & \\
\hline & $\begin{array}{l}\text { Duphaston } \\
\text { Norethindrone }\end{array}$ & \\
\hline & Norethisterone acetate & \\
\hline & Micronized progesterone & \\
\hline Melatonin therapy & & {$[98]$} \\
\hline (DHEA) & & {$[99,100]$} \\
\hline \multirow[t]{3}{*}{ Immunomodulation } & corticosteroid for immunosuppressive & {$[101,102]$} \\
\hline & monoclonal antibodies & \\
\hline & Extra-embryonic stem cells & {$[11,13,103-109]$} \\
\hline \multirow[t]{3}{*}{ Stem cell therapy } & Induced pluripotent stem cells & \\
\hline & Ovarian stem cell & \\
\hline & MSC & \\
\hline
\end{tabular}

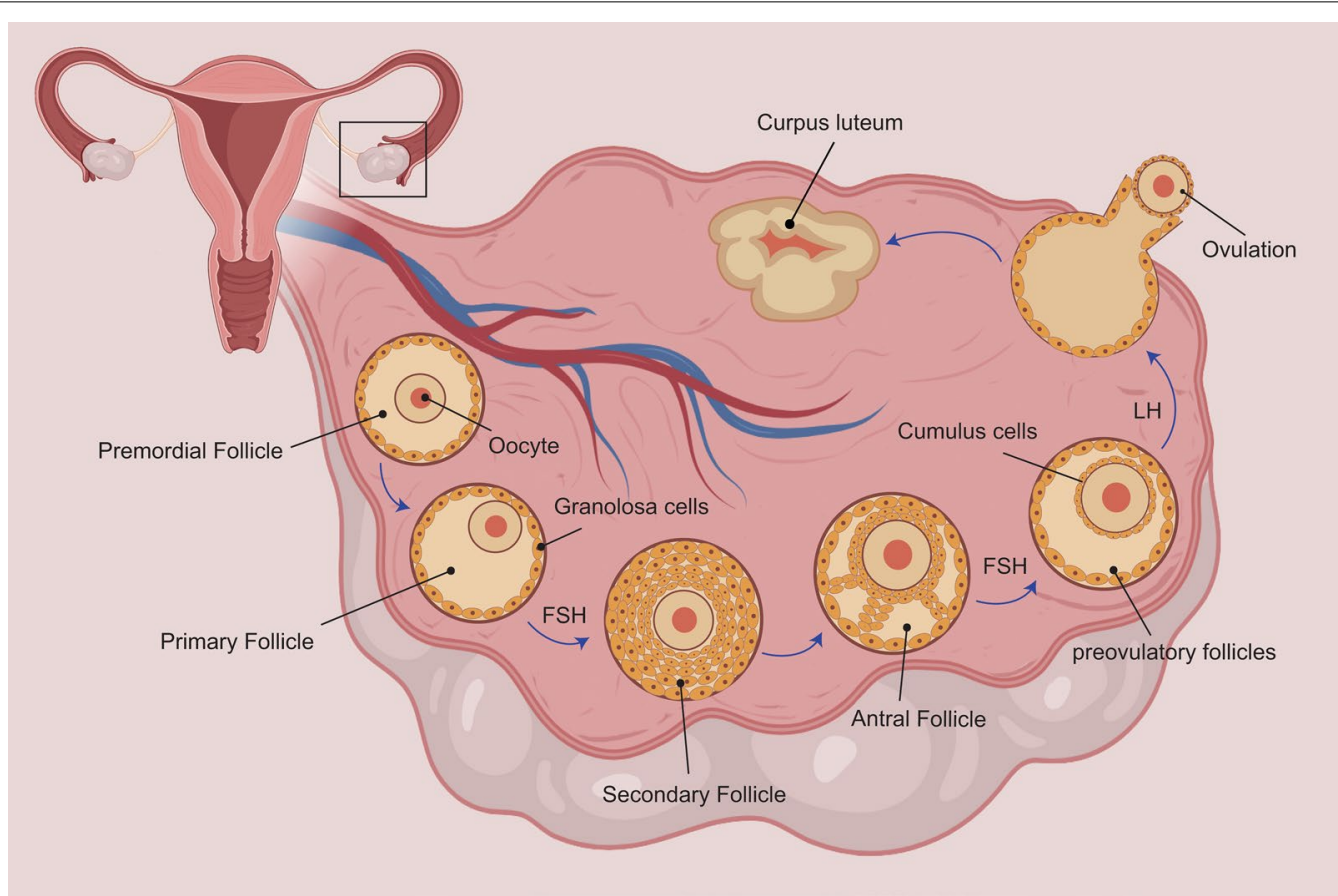

Fig. 1 Folliculogenesis: ovarian follicles enjoy an immature oocyte and somatic cells. Ovarian follicle maturation illustrates the passage of several small primordial follicles into pre-ovulatory follicle, which ultimately results in the maturation of oocyte

function [91]. Among viral infections, mumps erythema could cause POF. POF was reported in $3-7 \%$ of mumps patients during an epidemic [94].

\section{Treatment strategies}

Various treatment strategies have been performed due to the intricacy of POF disease. However, none of the 
treatments have been totally successful. Nonetheless, stem cell transplantation is the most effective method in this regard (Table 2) [95].

\section{Hormonal therapies}

Application of gonadal luteinization which maintains fertility hormone-releasing hormone (LHRHa) analogs, has been suggested to reduce the incidence of POF [95, 97, 110-114]. Sex steroid deficiency with endothelial dysfunction may increase the risk of cardiovascular disease and mortality in young women and might be associated with POF. Hormone therapy restores and improves endothelial function within 6 months of treatment [115]. Estrogens play an important role in the regulation of the GH/insulin-like growth factor I (IGF-I) axis [116]. Numerous studies have shown that besides its general beneficial effects, hormone replacement therapy (HRT) increases GH secretion and precedes GH stimulation testing in postmenopausal women [117]. Estrogen replacement is suggested to treat prevent bone loss and menopausal symptoms and improve cardiovascular health in POF patients [113]. Hormone therapy increases the risk of coronary artery disease $[118,119]$ associated with heart disease, stroke, venous thrombosis, endometrium, breast and ovarian cancer [120-122]. In postmenopausal women, evidence of hormone-related risks in women with POF is limited. However, it is believed that the absolute risk of infection is lower in these young women and therefore the benefit/risk ratio may be higher than in older women [123].

\section{Melatonin}

Studies have shown that melatonin increases gonadotropin levels [124], thyroid function [125], and recovery of fertility and menstruation [126]. Due to the presence of $\mathrm{FSH}, \mathrm{LH}$, androgen, and estrogen receptors on the pineal gland, it has been shown to be involved in folliculogenesis [98]. Recently, it has been shown that melatonin is produced in various tissues including reproductive tissues such as ovary and placenta $[127,128]$. As the ovaries cannot produce this hormone, melatonin, which can be found in the follicular fluid, comes from blood, and the mature follicles are most probably able to accumulate it. It seems that melatonin can support ovulation [78]. Melatonin regulates the immune system both in vitro and in vivo, stimulating nonspecific humoral and cell-mediated immunity as well as antibody-mediated immunity. For this, the reason is that melatonin has been used to treat cancer [78]. The antioxidant effects and protective properties of melatonin DNA on follicles can be beneficial for female cancer survivors and prevent chemotherapy-induced fertility loss as well as premature ovarian failure [129].

\section{Dehydroepiandrosterone (DHEA)}

As an endogenous steroid, dehydroepiandrosterone (DHEA) is derived from the zona reticularis of the ovarian monocytes and adrenal cortex in women [130]. It is very important in peripheral tissues and is produced by the conversion of cholesterol [131]. Thus, DHEA acts as a vital prohormone in ovarian follicular steroidogenesis [99]. Studies have shown that DHEA administration in patients with premature ovarian failure increases the risk of pregnancy, reduces the risk of miscarriage by reducing aneuploidy, and makes IVF treatment more successful $[78,100]$. DHEA also appears to objectively improve ovarian storage. Recent animal data support androgens in enhancing pre-cleft follicle growth and reducing follicular atresia [132].

\section{Immunomodulation}

POF treatment through immune modulation is an effective method when POF is caused by ovarian autoimmune damage [133]. Some autoantibodies that have been identified in POF are steroid-producing cell antibodies, and this antibody binds to corpus luteum, granulosa cells, hilar cells, and theca cells [111]. In this regard, monoclonal antibodies and corticosteroids are used to treat immunosuppression [101, 102, 111, 133]. Furthermore, a return of ovarian function has been observed in patients treated for myasthenia gravis using thymectomy [78]. Due to ovarian autoimmune damage, monoclonal antibodies (e.g., etanercept) are used when treating POF [78, 102, 134].

\section{Stem cell therapy}

Due to the increased risk of cancer after using hormone replacement therapeutic and due to other side effects infertility treatments scientists have proposed other treatments, such as stem cell therapy $[135,136]$. Stem cells enjoy the ability to self-repair and regenerate and are effective in treating infertility and ovarian failure $[11,137]$. Recent studies on animal models of POF have shown that ovarian structure and function may improve with stem cell therapy, which could thus be an effective treatment for premature ovarian failure [138-140]. Stem cells used to treat POF include:

\section{Extra-embryonic stem cells}

Amniotic fluid stem cells are a multipotent population obtained from the extra-embryonic layer and proliferate faster than mesenchymal stem cells [13]. Amniotic fluid stem cell transplantation inhibits follicle atresia and maintains healthy follicles $[103,104,141,142]$. 


\section{Induced pluripotent stem cells}

The use of human-derived ovarian granulosa cells from human-induced pluripotent stem cells could cause growth in ovarian tissue. The expression of ovarian granulosa cell markers decreases atretic follicle number and increases estradiol [11].

\section{Mesenchymal stem cell}

Many researchers consider mesenchymal stem cell (MSC) transplantation as the best and most successful method for cell therapy $[1,106]$. Since these cells simultaneously activate several mechanisms (trophic, paracrine, immune modulation, and differentiation), they affect and improve all stages of the regeneration of damaged tissue [107]. Many researches have demonstrated that MSCs might be present throughout the body in any vascularized tissue [107]. Bone marrow-derived MSCs (BMMSCs) are described as the "gold standard" of historically accepted MSCs [107-109]. However, there is currently active research on mesenchymal stem cells from other sources, including adipose tissue, amniotic fluid, peripheral blood and umbilical cord, tooth pulp, skin, umbilical cord tissue, synovium, placenta, endometrium, etc. [107, 143-148].

The focus of our study is on umbilical cord-derived mesenchymal stem cells (UC-MSCs), which possess an exceptional combination of prenatal and postnatal stem cell characteristics [149].

\section{HUCMSCs therapy}

\section{Source}

A promising source for MSCs is the human umbilical cord [150]. Unlike bone marrow stem cells, the method of collecting MSCs from human umbilical cord is faster and painless [151]. Other cells have also been reported in parts of the umbilical cord, such as vascular tissue and Wharton jelly $[152,153]$. These cells have the triple activity of tissue repair, modulation of immune responses, and anti-cancer properties. HUCMCs can also be the nutrient layer of other pluripotent stem cells or embryonic stem cells [149].

Wharton umbilical cord jelly contains fibroblast-like cells and mucoid connective tissue [150]. Through the analyses of flow cytometry, it was discovered that mesenchymal cells derived from umbilical cord oxide matrix receptors (CD44, CD105) and integrin markers (CD29, CD51) are not hematopoietic markers (CD34, CD45) [150].

\section{The importance of UCMSC}

Human mesenchymal stem cells (MSCs) have recently received a great deal of attention due to their enormous therapeutic potential. Less ethical issues, painless obtaining of the abandoned umbilical cord, and lack of immunity are prominent benefits of hUCMSC compared to other MSC resources [154]. The ability to modulate immune responses makes hUCMSC an important stem cell resource for allogeneic transplantation without immunosuppression [155]. There is no evidence of an immunological response and no evidence of increased dose and frequency of hUCMSCs used in patients [156]. Based on the evidence gathered, stem cells improve ovarian function due to their paracrine effects rather than differentiating into specific cells [157]. Studies on stem cell-derived secretory agents report that the secretion of microscopes and exosomes is present in the stem cell culture medium known as the conditioned medium (CM) [158]. The contents of these vesicles secreted by mesenchymal stem cells (MSCs) include cytokines and growth factors, signaling lipids, messenger RNAs (mRNAs), and regulatory miRNAs [159]. These factors are involved in cell-cell communication, cellular signaling, and changes in cell or tissue metabolism. CM can enhance tissue/limb repair under different conditions [160]. CM has several advantages over stem cells. CM eliminates stem cell side effects on tumor cells, such as differentiation into other stromal cells, enhances the metastatic capabilities of tumor cells, and stimulates epithelial-mesenchymal transmission of tumor cells [161, 162]. hUCMSC-CM can regulate G-CSF expression in granulosa cells and reduce granulosa cell apoptosis [163]. The anti-apoptotic effects of G-CSF have been reported in vascular endothelial cells, heart and nerve cells [164]. The PI3K/Akt pathway is activated in granulosa cells, thereby reducing granulosa cell apoptosis [165]. In addition, hUCMSCs have multifunctional stem cell characteristics that can be differentiated into several breeds under different conditions of differentiation [166, 167]. Some studies have also shown that hUCMSCs differentiate into oocyte-like structures and express germ cell-specific mRNA and protein markers. hUCMSC increases the proliferation of damaged human endometrial stromal cells (ESCs) and significantly reduces the percentage of apoptosis when cultured with them [168]. hUCMSC may restore endometrial damage through secretion of vascular endothelial growth factor (VEGF) and anti-apoptosis [169]. In one study, POF model rats were injected with different concentrations of UCMSC. Follicular morphology, ovarian function, hormonal secretion, and proliferation and apoptosis of granulosa cells were assessed. It was demonstrated that follicular growth was considerably enhanced after UCMSC transplantation and rat estrous cycle returned to normal. Moreover, the levels of progesterone (P4), estradiol (E2), and antimalarial hormone (AMH) were significantly increased $[170,171]$ in the serum. UCMSC transplantation also reduces granulosa cell 
apoptosis and granulosa cell proliferation [22]. These results further confirm the increase in tissue regeneration and cellular growth factors and present theoretical foundations for applying stem cells clinically to treat POF [171-174]. HUCMSC transplantation can also restore chemotherapy-damaged ovaries. Improved ovarian function in the rat model of premature ovarian failure (POF) is largely due to cytokines produced by hUCMSCs through the paracrine mechanism rather than direct differentiation into germ cells [175]. In the process of transplantation, endometrial acceptance refers to the ability of the endometrium to allow embryos to implant during a particular period [176, 177]. Embryo implantation is similar to allograft transplantation, which is also a complex process involving many immune system regulating factors such as Th1/Th2 cytokine imbalances. Natural uterine killer cells (uNK) play an important role in maintaining the Th1/Th2 cytokine balance in the local endometrial immune response. uNK cells are a group of specific cells in the endometrial stroma where most uNK cell phenotypes are stained as CD56+CD16- [178180]. uNK cells proliferate rapidly in the secretory stage and early pregnancy. If uNK cells are activated by certain pathological factors, the cells secrete cytotoxic factors to lead to an imbalance of Th1/Th2 cytokines. Consequently, this reduces the effect of Th1 cytokines on endometrial receptivity and embryo implantation failure [180, 181]. As reported, changes in endometrial acceptance depend on the specific spatial and temporal expression of certain gene sets in the endometrium. Among them, the HOXA10 gene is used as a molecular marker to measure endometrial receptivity [182]. Some studies have shown that large numbers of immune cells invade ovarian tissue in mice with premature insufficiency, including $\mathrm{T}$ lymphocytes [183, 184], B lymphocytes, and normal killer cells [25]. It has also been reported that the balance of Th1/Th2 cytokine expression in the $\mathrm{T}$ lymphocyte subtype is abnormal in patients with POF [185]. Studies have shown that immune regulation in Th1/Th2 cytokine balance and uNK cell expression is involved in improving ovarian function and improving endometrial receptivity after hUCMSC transplantation in POF mice [186]. In 2019, Yang Lei et al. used a collagen scaffold filled with hUCMSCs (collagen/hUCMSC) in ovulating POF mice (six-week-old female C57BL/6 mice), which maintained ovarian function, and enhanced anti-Mullerian hormone $(\mathrm{AMH})$ and estrogen (E2) levels. It also increased the volume of ovaries and the amount of antral follicles. Immunohistochemical assessment showed that collagen/h-UC-MSC transplantation promoted granulosa cell proliferation, which is crucial for follicle maturation [171]. In 2020, Wang Wei et al. used different concentrations of UCMSC in POF rats (female rats). It was shown that the estrous cycle of rats was restored to natural, and follicular growth was considerably enhanced following UCMSC transplantation. Moreover, the levels of progesterone (P4), 17-estradiol (E2), and anti-molar hormone $(\mathrm{AMH})$ were considerably increased in the serum. UCMSC transplantation, likewise, reduced granulosa cell apoptosis and proliferation [172]. In 2020, Shen and Dai Cao used HUCMSCs in POF mice (female $\mathrm{BALB} / \mathrm{c}$ mice) with the aim of repairing ovarian injury following chemotherapy. It has been demonstrated by several experiments that umbilical cord-transplanted stem cells are capable of proliferating and migrating into the ovaries, improving ovarian function, increasing the amount of follicles and granulosa cells on all ovary levels, and improving endocrine function [173]. In 2020, Yin Wu et al. used UCMSCs to restore the ovarian function in POF mice (C57BL/6). Transplantation increases the number of functional follicles and the regular production of hormones [187]. In 2019, Zheng Fu et al. used UCMSC transplantation after chemotherapy-induced ovarian damage. The study showed that UCMSC transplantation improves folliculogenesis and disturbed secretion of hormones in POF mice (C57BL/6) [106]. In 2019, Yang Du et al. used HUCMSC-MVs to restore ovarian function in a female mouse model with chemotherapy-induced POI. The results showed that HUCMSC-MV transplantation can increase weight of the body, enhance the amount of ovarian follicles (early follicles, growing and ovulating before ovulation), stimulate ovarian angiogenesis, and restore the unstable estrous cycle of POI mice [188]. In 2019, Jalalie Rezaie et al. used human umbilical cord vein MSCs (HUCV-MSCs) in several parts of the ovarian tissue in mice (adult female C57BL/6 mice) who had cyclophosphamide (CTX)-induced POF. The results showed that MSCs were capable of migrating to injured tissues and repairing them through the modulation of immune system and secretion of growth factors [189]. In 2016, Elfayomy Almasry et al. used the human umbilical cord blood (HCB) MSCs to evaluate their effect on ovarian epithelium following paclitaxel-induced ovarian failure in POF rats. The results showed that HCB-MSCs were capable of restoring ovarian function following paclitaxel injection [190]. In 2013, Wang Yu et al. used UCMSC to treat POF rat models and the results

\section{Methods}

To model POF mice, random division of the female $\mathrm{BALB} / \mathrm{c}$ mice into two groups was performed: the control group and the POF group. POF mice were injected with CTX intraperitoneum. The control group was injected with normal saline instead of CTX, without there being any treatment or negative control [149, 192]. Infant cord tissue was taken with the consent of the donor. Manual 


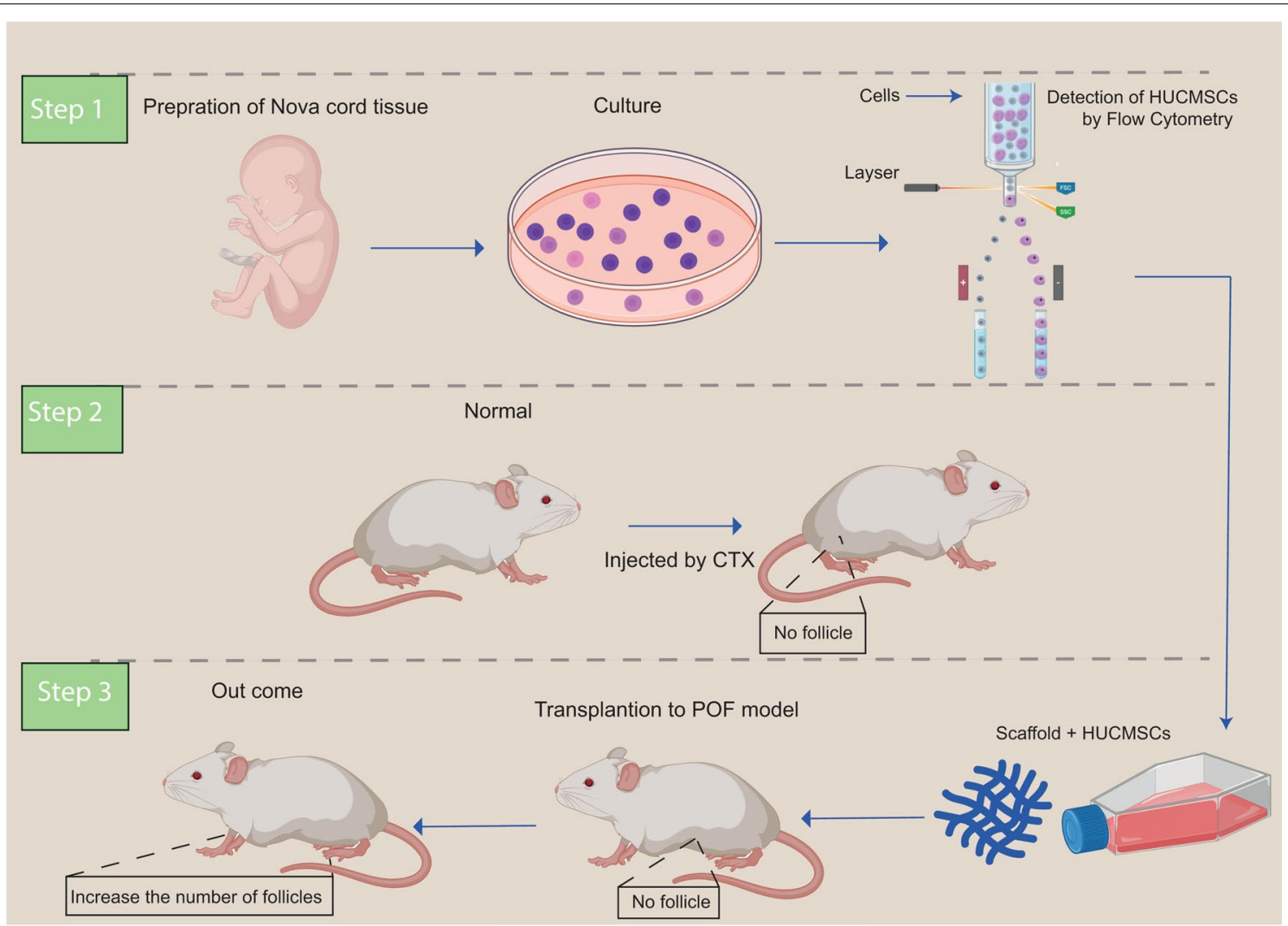

Fig. 2 The use of stem cell therapy to treat POF. The application of stem cells for the treatment of POF mice and renewing follicles after stem cell transplantation. Stem cell therapy results in the treatment of POF mice

dissection of the umbilical cord into small parts was performed. Tissues fragments were cultured in low glucose Dulbecco's modified Eagle's medium and with fetal bovine serum penicillin, combined with streptomycin. After obtaining HUCMSC colonies, flow cytometry was used for the analysis of UC-MSC level markers. Cells with (PE) and (FITC) against human CD13,CD34,CD45, CD73, CD90, CD105, CD146, and HLADR were incubated [190]. Scaffolds (collagen type 1) were prepared from the molecule laboratory $[171,193]$. Collagen/UCMSC transplantation was performed for mice [2, 171, 175, 190]. Following transplantation, rat hormone levels and number of ovarian follicles were measured, and ovarian morphology was assessed by hematoxylin and eosin (HE) staining (Fig. 2) [175].

\section{Conclusion}

POF hugely affects mental and physical health of young women. Women with this condition usually use hormone therapy to reduce the symptoms of estrogen deficiency, which is not very effective. Therefore, we must look for better alternatives to treat the disease. Many studies have been performed in this field, the results of which propose stem cell therapy as more effective compared to other methods. Since these cells have the potential for selfimprovement and regeneration and can improve ovarian function, increase the number of follicles, increase sex hormone levels, and reduce granulosa cell apoptosis, they could be employed to treat POF and infertility. In most studies, mesenchymal stem cells are used due to the facile access to these cells and their differentiation in most tissues. Our study was focused on mesenchymal cells derived from the human umbilical cord. Researchers have achieved decent results in this field, and thus, it is hoped that researchers can find a definite cure for this disease.

\footnotetext{
Abbreviations

AMH: Anti-Müllerian hormone; BM-MSCs: Bone marrow mesenchymal stem cells; CTX: Cyclophosphamide; DHEA: Dehydroepiandrosterone; E2: Estradiol; FITC: Fluorescein isothiocyanate; FSH: Follicle-stimulating hormone; HCB: Hexachlorobenzene; HE: Hematoxylin and eosin; HPV: Human papillomavirus infection; HUCMSC: Human umbilical cord mesenchymal stem cells; HUCMSCMVs: Human umbilical cord mesenchymal stem cell-derived microvesicles; LH: Luteinizing hormone; LHRHa: Luteinizing hormone-releasing hormone analog; Name: Mesenchymal stem celli; P4: Progesterone; PE: Phycoerythrin; POF: Premature ovarian failure; POI: Premature ovarian insufficiency; UC-MSCs: Umbilical cord mesenchymal stem cells; VEGF: Vascular endothelial growth factor.
} 


\section{Acknowledgements}

This work was supported by the Stem Cell Research Center (SCRC), Tabriz University of Medical Sciences, Tabriz, Iran.

\section{Authors' contributions}

Oldouz shareghi oskoue made contributions to the writing of the manuscript, the design of the figures. Leili Aghebati-Maleki and Mehdi Yousefi contributed to the study design and revised of the manuscript. All authors have approved the submitted version of the article and have agreed to be personally accountable for the author's own contributions and to ensure that questions related to the accuracy or integrity of any part of the work. All authors read and approved the final manuscript.

\section{Funding}

This study was supported by the Stem Cell Research Center (SCRC), Tabriz University of Medical Sciences, Tabriz, Iran [Grant No. 65863].

\section{Availability of data and materials}

Data sharing is not applicable to this article as no new data were created or analyzed in this study.

\section{Declarations}

\section{Ethics approval and consent to participate}

Not applicable.

\section{Consent for publication}

Not applicable.

\section{Competing interests}

The authors declare that they have no competing interests.

\section{Author details}

${ }^{1}$ Stem Cell Research Center, Tabriz University of Medical Science, Tabriz, Iran. ${ }^{2}$ Student's Research Committee, Tabriz University of Medical Sciences, Tabriz, Iran. ${ }^{3}$ Immunology Research Center, Tabriz University of Medical Sciences, Tabriz, Iran. ${ }^{4}$ Department of Immunology, School of Medicine, Faculty of Medicine, Tabriz University of Medical Sciences, Tabriz, Iran.

Received: 2 May 2021 Accepted: 2 June 2021

Published online: 11 August 2021

\section{References}

1. Liu T, et al. CD44+/CD105+ human amniotic fluid mesenchymal stem cells survive and proliferate in the ovary long-term in a mouse model of chemotherapy-induced premature ovarian failure. Int J Med Sci. 2012;9(7):592.

2. Liu T, et al. Transplantation of human menstrual blood stem cells to treat premature ovarian failure in mouse model. Stem Cells Dev. 2014;23(13):1548-57.

3. Słopień R, Warenik-Szymankiewicz A. Premature ovarian failure: diagnosis and treatment. Clin Exp Obstet Gynecol. 2014;41(6):659.

4. Komorowska B. Autoimmune premature ovarian failure. Przeglad Menopauzalny Menopause Review. 2016;15(4):210.

5. Ayesha VJ, Goswami D. Premature ovarian failure: an association with autoimmune diseases. J Clin Diagn Res. 2016;10(10):QC10.

6. Fu X, et al. Overexpression of miR-21 in stem cells improves ovarian structure and function in rats with chemotherapy-induced ovarian damage by targeting PDCD4 and PTEN to inhibit granulosa cell apoptosis. Stem Cell Res Ther. 2017;8(1):1-13.

7. Kumar M, et al. Chromosomal abnormalities \& oxidative stress in women with premature ovarian failure (POF). Indian J Med Res. 2012;135(1):92.

8. Chen $L$, et al. Effect of stem cell transplantation of premature ovarian failure in animal models and patients: a meta-analysis and case report. Exp Ther Med. 2018;15(5):4105-18.
9. Lew R. Natural history of ovarian function including assessment of ovarian reserve and premature ovarian failure. Best Pract Res Clin Obstet Gynaecol. 2019;55:2-13.

10. Lissoni, S., et al. $X ; Y$ translocations and POF. in 6th European Cytogenetics Conference. 2007. Springer Netherlands.

11. Liu T, et al. Transplantation of ovarian granulosa-like cells derived from human induced pluripotent stem cells for the treatment of murine premature ovarian failure. Mol Med Rep. 2016;13(6):5053-8.

12. Beck-Peccoz P, Persani L. Premature ovarian failure. Orphanet J Rare Dis. 2006;1(1):9.

13. Sheikhansari $G$, et al. Current approaches for the treatment of premature ovarian failure with stem cell therapy. Biomed Pharmacother. 2018;102:254-62.

14. Xu M, et al. In vitro grown human ovarian follicles from cancer patients support oocyte growth. Hum Reprod. 2009;24(10):2531-40.

15. Rodgers RJ, Irving-Rodgers HF, Russell DL. Extracellular matrix of the developing ovarian follicle. Reprod Camb. 2003;126(4):415-24.

16. Richards JS. Maturation of ovarian follicles: actions and interactions of pituitary and ovarian hormones on follicular cell differentiation. Physiol Rev. 1980;60(1):51-89.

17. Van Den Hurk R, Zhao J. Formation of mammalian oocytes and their growth, differentiation and maturation within ovarian follicles. Theriogenology. 2005;63(6):1717-51.

18. DiZerega GS, Hodgen GD. Folliculogenesis in the primate ovarian cycle. Endocr Rev. 1981;2(1):27-49.

19. Dizerega GS, et al. Suppression of follicle-stimulating hormonedependent folliculogenesis during the primate ovarian cycle. J Clin Endocrinol Metabol. 1981;52(3):451-6.

20. Kimura S, et al. Androgen receptor function in folliculogenesis and its clinical implication in premature ovarian failure. Trends Endocrinol Metab. 2007:18(5):183-9.

21. Grier HJ, Neidig CL, Quagio-Grassiotto I. Development and fate of the postovulatory follicle complex, postovulatory follicle, and observations on folliculogenesis and oocyte atresia in ovulated common snook, Centropomus undecimalis (Bloch, 1792). J Morphol. 2017;278(4):547-62.

22. Wang, S., et al., The therapeutic potential of umbilical cord mesenchymal stem cells in mice premature ovarian failure. Biomed Res Int. 2013; 2013.

23. Goswami R, et al. Prevalence of thyroid autoimmunity in sporadic idiopathic hypoparathyroidism in comparison to type 1 diabetes and premature ovarian failure. J Clin Endocrinol Metab. 2006;91(11):4256-9.

24. Dragojević-Dikić $S$, et al. An immunological insight into premature ovarian failure (POF). Autoimmun Rev. 2010;9(11):771-4.

25. Chernyshov VP, et al. Immune disorders in women with premature ovarian failure in initial period. Am J Reprod Immunol. 2001;46(3):220-5.

26. Unuane D, et al. Endocrine disorders \& female infertility. Best Pract Res Clin Endocrinol Metab. 2011;25(6):861-73.

27. Ruggeri RM, Giuffrida G, Campenni A. Autoimmune endocrine diseases Miner Endocrinol. 2018;43(3):305.

28. Visser JA, Themmen AP. Anti-Müllerian hormone and folliculogenesis. Mol Cell Endocrinol. 2005;234(1-2):81-6.

29. Chen Z, et al. Rictor/mTORC2 pathway in oocytes regulates folliculogenesis, and its inactivation causes premature ovarian failure. J Biol Chem. 2015;290(10):6387-96.

30. Nippita T, Baber R. Premature ovarian failure: a review. Climacteric. 2007;10(1):11-22

31. Vegetti $W$, et al. Inheritance in idiopathic premature ovarian failure: analysis of 71 cases. Human Reprod (Oxford, England) 1998;13(7):1796-800

32. Goswami D, Conway GS. Premature ovarian failure. Hum Reprod Update. 2005;11(4):391-410

33. Woad KJ, et al. The genetic basis of premature ovarian failure. Aust N Z J Obstet Gynaecol. 2006;46(3):242-4.

34. Shelling AN. X chromosome defects and premature ovarian failure. Aust N Zeal J Med. 2000;30(1):5-7.

35. Qin, Y., Simpson, J. L., Chen, Z.-J. Genetics of premature ovarian failure: new developments in etiology In: Genetics of human infertility. 2017, Karger Publishers, pp. 17-39.

36. Franić-Ivanišević $M$, et al. Genetic etiology of primary premature ovarian insufficiency. Acta Clin Croat. 2016;55(4):629-35. 
37. Uzielli MG, et al. Premature ovarian failure (POF) and fragile $X$ premutation females: from POF to fragile $X$ carrier identification, from fragile $X$ carrier diagnosis to POF association data. Am J Med Genet. 1999;84(3):300-3.

38. Giovannucci Uzielli M, et al. Premature ovarian failure (POF) and fragile $X$ premutation females: from $P O F$ to fragile $X$ carrier identification, from fragile X carrier diagnosis to POF association data. Am J Med Genet. 1999;84(3):300-3.

39. Bione S,Toniolo, D. X chromosome genes and premature ovarian failure. In: Seminars in reproductive medicine. 2000. Copyright $\odot 2000$ by Thieme Medical Publishers, Inc., 333 Seventh Avenue, New

40. Pouresmaeili F, Fazeli Z. Premature ovarian failure: a critical condition in the reproductive potential with various genetic causes. Int J Fertil Steril. 2014:8(1):1.

41. Saranya $B$, et al. Translocation $t(X ; 11)(q 22 ; q 25)$ in a woman with premature ovarian failure. Sexual Dev. 2013;7(4):216-21.

42. Bertini $V$, et al. Molecular cytogenetic definition of a translocation t $(X ; 15)$ associated with premature ovarian failure. Fertil Steril. 2010;94(3):1097.e5.

43. Toniolo D, Rizzolio F. X chromosome and ovarian failure. In: Seminars in reproductive medicine. 2007. Copyright@ 2007 by Thieme Medical Publishers, Inc., 333 Seventh Avenue, New ....

44. Schlessinger D, et al. Genes and translocations involved in POF. Am J Med Genet. 2002;111(3):328-33.

45. Devi A, Benn P. X-chromosome abnormalities in women with premature ovarian failure. J Reprod Med. 1999;44(4):321-4.

46. Castillo S, et al. The cytogenetics of premature ovarian failure. Rev Chil Obstet Ginecol. 1992;57(5):341-5.

47. Zinn AR. The X chromosome and the ovary. J Soc Gynecol Investig 2001;8(1_suppl):S34-6.

48. Hook E, Warburton D. The distribution of chromosomal genotypes associated with Turner's syndrome: livebirth prevalence rates and evidence for diminished fetal mortality and severity in genotypes associated with structural X abnormalities or mosaicism. Hum Genet. 1983;64(1):24-7.

49. Zinn AR, Ross JL. Turner syndrome and haploinsufficiency. Curr Opin Genet Dev. 1998;8(3):322-7.

50. Loughlin S, et al. Analysis of the origin of Turner's syndrome using polymorphic DNA probes. J Med Genet. 1991;28(3):156-8.

51. Hoyos LR, Thakur M. Fragile $X$ premutation in women: recognizing the health challenges beyond primary ovarian insufficiency. J Assist Reprod Genet. 2017:34(3):315-23.

52. Oberle I, et al. Instability of a 550-base pair DNA segment and abnormal methylation in fragile X syndrome. Science. 1991;1991:1097-102.

53. Verkerk AJ, et al. Identification of a gene (FMR-1) containing a CGG repeat coincident with a breakpoint cluster region exhibiting length variation in fragile X syndrome. Cell. 1991;65(5):905-14.

54. Sherman SL. Premature ovarian failure in the fragile $X$ syndrome. Am J Med Genet. 2000:97(3):189-94.

55. Macpherson J, et al. Fragile $X$ syndrome: of POF and premutations. J Med Genet. 1999:36(2):171-2.

56. Welt $C$, Smith $P$, Taylor A. Evidence of early ovarian aging in fragile $X$ premutation carriers. J Clin Endocrinol Metab. 2004:89(9):4569-74.

57. Laml T, et al. Genetic disorders in premature ovarian failure. Hum Reprod Update. 2002;8(5):483-91.

58. Kaufman FR, et al. Correlation of cognitive, neurologic, and ovarian outcome with the Q188R mutation of the galactose-1-phosphate uridyltransferase gene. J Pediatr. 1994;125(2):225-7.

59. Nelson LM. Autoimmune ovarian failure: comparing the mouse mode and the human disease. J Soc Gynecol Investig. 2001;8(1_suppl):S55-7.

60. Bakalov VK, et al. Autoimmune oophoritis as a mechanism of follicular dysfunction in women with 46, XX spontaneous premature ovarian failure. Fertil Steril. 2005;84(4):958-65.

61. Lebovic DI, Naz R. Premature ovarian failure: Think'autoimmune disorder.'Sex Reprod Menopause. 2004;2(4):230-3.

62. Schoemaker J, Drexhage H, Hoek A, Premature ovarian failure and ovarian autoimmunity. Endocrine reviews, 1997.

63. Goswami D, Conway GS. Premature ovarian failure. Hormone Res Paediatr. 2007;68(4):196-202.

64. Santoro N. Research on the mechanisms of premature ovarian failure. J Soc Gynecol Investig. 2001;8(1):S10-2.
65. Nelson LM, Covington SN, Rebar RW. An update: spontaneous premature ovarian failure is not an early menopause. Fertil Steril. 2005:83(5):1327-32

66. Dawood AS, et al. Premature ovarian failure of autoimmune etiology in 46XX patients: is there a hope? J Complem Integr Med. 2018;15:4.

67. Labarbera AR, et al. Autoimmune etiology in premature ovarian failure. Am J Reprod Immunol Microbiol. 1988;16(3):115-22.

68. Zirilli $G$, et al. Peculiarities of autoimmune polyglandular syndromes in children and adolescents. Acta Bio Medica: Atenei Parmensis. 2017:88(3):271.

69. Biglieri EG, Herron MA, Brust N. 17-hydroxylation deficiency in man. J Clin Investig. 1966;45(12):1946-54.

70. Pellicer $A$, et al. In vitro fertilization as a diagnostic and therapeutic tool in a patient with partial 17, 20-desmolase deficiency. Fertil Steril. 1991;55(5):970-5.

71. Falorni A, et al. Steroid-cell autoantibodies are preferentially expressed in women with premature ovarian failure who have adrenal autoimmunity. Fertil Steril. 2002;78(2):270-9.

72. Kominami S, Shinzawa K, Takemori S. Purification and some properties of cytochrome P-450 specific for steroid 17a-hydroxylation and C17. C20 bond cleavage from guinea pig adrenal microsomes. Biochem Biophys Res Commun. 1982;109(3):916-21.

73. Kaufman FR, et al. Male pseudohermaphroditism due to 17, 20-desmolase deficiency. J Clin Endocrinol Metab. 1983;57(1):32-6.

74. Rabinovici J, et al. In vitro fertilization and primary embryonic cleavage are possible in 17 a-hydroxylase deficiency despite extremely low intrafollicular 17 ß-estradiol. J Clin Endocrinol Metabol. 1989;68(3):693-7.

75. De Peretti E, Pradon M, Forest M. 17, 20-desmolase deficiency in a female newborn, paradoxically virilized in utero. J Steroid Biochem. 1984;20(1):455-8

76. Mallín SR. Congenital adrenal hyperplasia secondary to 17-hydroxylase deficiency: two sisters with amenorrhea, hypokalemia, hypertension, and cystic ovaries. Ann Intern Med. 1969;70(1):69-75.

77. Colafrancesco S, et al. Human papilloma virus vaccine and primary ovarian failure: another facet of the autoimmune/inflammatory syndrome induced by adjuvants. Am J Reprod Immunol. 2013;70(4):309-16.

78. Jankowska K. Premature ovarian failure. Przeglad menopauzalny Menopause Review. 2017;16(2):51.

79. Little DT, Ward HRG. Premature ovarian failure 3 years after menarche in a 16-year-old girl following human papillomavirus vaccination. Case Reports. 2012;2012:BCR2012006879.

80. Lie Fong $\mathrm{S}$, et al. Anti-müllerian hormone as a marker of ovarian function in women after chemotherapy and radiotherapy for haematological malignancies. Hum Reprod. 2008;23(3):674-8.

81. Larsen EC, et al. Reduced ovarian function in long-term survivors of radiation-and chemotherapy-treated childhood cancer. J Clin Endocrinol Metab. 2003;88(11):5307-14.

82. Yucebilgin MS, et al. Effect of chemotherapy on primordial follicular reserve of rat: an animal model of premature ovarian failure and infertility. Aust N Z J Obstet Gynaecol. 2004;44(1):6-9.

83. Blumenfeld Z, Eckman A. Preservation of fertility and ovarian function and minimization of chemotherapy-induced gonadotoxicity in young women by GnRH-a. JNCI Monogr. 2005;2005(34):40-3.

84. Guerreiro DD, et al. In situ cultured preantral follicles is a useful model to evaluate the effect of anticancer drugs on caprine folliculogenesis. Microsc Res Technol. 2016;79(8):773-81.

85. Lambertini M, et al. Ovarian suppression using luteinizing hormonereleasing hormone agonists during chemotherapy to preserve ovarian function and fertility of breast cancer patients: a meta-analysis of randomized studies. Ann Oncol. 2015;26(12):2408-19.

86. Yang B, et al. Concurrent treatment with gonadotropin-releasing hormone agonists for chemotherapy-induced ovarian damage in premenopausal women with breast cancer: a meta-analysis of randomized controlled trials. The Breast. 2013;22(2):150-7.

87. Tao $X$, et al. Effect of primary ovarian insufficiency and early natural menopause on mortality: a meta-analysis. Climacteric 2016;19(1):27-36.

88. Vabre P, et al. Environmental pollutants, a possible etiology for premature ovarian insufficiency: a narrative review of animal and human data. Environ Health. 2017;16(1):37. 
89. Ebrahimi M, Asbagh FA. Pathogenesis and causes of premature ovarian failure: an update. International journal of fertility \& sterility. 2011;5(2):54.

90. Kaufman DW, et al. Cigarette smoking and age at natural menopause. Am J Public Health. 1980;70(4):420-2.

91. Di Prospero F, Luzi S, lacopini Z. Cigarette smoking damages women's reproductive life. Reprod Biomed Online. 2004;8(2):246-7.

92. Cramer DW, et al. Cross-sectional and case-controlled analyses of the association between smoking and early menopause. Maturitas. 1995;22(2):79-87.

93. Mattison D, Thorgeirsson S. Smoking and industrial pollution, and their effects on menopause and ovarian cancer. The Lancet. 1978;311(8057):187-8.

94. Rebar RW, Connolly HV. Clinical features of young women with hypergonadotropic amenorrhea. Fertil Steril. 1990;53(5):804-10.

95. Hewlett M, Mahalingaiah S. Update on primary ovarian insufficiency. Curr Opin Endocrinol Diabetes Obes. 2015;22(6):483.

96. Kalantaridou SN, Davis SR, Nelson LM. Premature ovarian failure. Endocrinol Metab Clin N Am. 1998;27(4):989-1006.

97. Del Mastro L, et al. Gonadotropin-releasing hormone analogues for the prevention of chemotherapy-induced premature ovarian failure in cancer women: systematic review and meta-analysis of randomized trials. Cancer Treat Rev. 2014;40(5):675-83.

98. Bellipanni $\mathrm{G}$, et al. Effects of melatonin in perimenopausal and menopausal women: a randomized and placebo controlled study. Exp Gerontol. 2001;36(2):297-310.

99. Mamas L, Mamas E. Premature ovarian failure and dehydroepiandrosterone. Fertil Steril. 2009;91(2):644-6.

100. Qin J, Fan L, Qin A. The effect of dehydroepiandrosterone (DHEA) supplementation on women with diminished ovarian reserve (DOR) in IVF cycle: evidence from a meta-analysis. J Gynecol Obstetr Hum Reprod. 2017;46(1):1-7.

101. Cowchock FS, McCabe JL, Montgomery BB. Pregnancy after corticosteroid administration in premature ovarian failure (polyglandular endocrinopathy syndrome). Am J Obstet Gynecol. 1988;158(1):118-9.

102. Gleicher N. Some thoughts on the reproductive autoimmune failure syndrome (RAFS) and Th- 1 versus Th-2 immune responses. Am J Reprod Immunol. 2002;48(4):252-4.

103. De Coppi $\mathrm{P}$, et al. Isolation of amniotic stem cell lines with potential for therapy. Nat Biotechnol. 2007;25(1):100-6.

104. Xiao G-Y, et al. Amniotic fluid stem cells prevent follicle atresia and rescue fertility of mice with premature ovarian failure induced by chemotherapy. PLOS ONE. 2014;9(9):e106538.

105. Liu M, et al. Small extracellular vesicles derived from embryonic stem cells restore ovarian function of premature ovarian failure through PI3K AKT signaling pathway. Stem Cell Res Ther. 2020;11(1):1-12.

106. Zheng, Q., et al., Umbilical cord mesenchymal stem cell transplantation prevents chemotherapy-induced ovarian failure via the NGF/TrkA pathway in rats. BioMed Res Int. 2019;2019.

107. Arutyunyan, I., et al., Umbilical cord as prospective source for mesenchymal stem cell-based therapy. Stem Cells Int. 2016;2016.

108. Liu J, et al. Homing and restorative effects of bone marrow-derived mesenchymal stem cells on cisplatin injured ovaries in rats. Mol Cells. 2014;37(12):865.

109. Drela K, et al. Bone marrow-derived from the human femoral shaft as a new source of mesenchymal stem/stromal cells: an alternative cell material for banking and clinical transplantation. Stem Cell Res Ther. 2020;11(1):1-13

110. Chen, $\mathrm{H}_{\text {., }}$ et al., Adjuvant gonadotropin-releasing hormone analogues for the prevention of chemotherapy-induced premature ovarian failure in premenopausal women. Cochrane Database of Syst Rev. 2019;3.

111. Sluss PM, Schneyer AL. Low molecular weight follicle-stimulating hormone receptor binding inhibitor in sera from premature ovarian failure patients. J Clin Endocrinol Metab. 1992;74(6):1242-6.

112. Dragojević-Dikić S, et al. Hormone replacement therapy and successful pregnancy in a patient with premature ovarian failure. Gynecol Endocrinol. 2009;25(12):769-72.

113. Cartwright $B$, et al. Hormone replacement therapy versus the combined oral contraceptive pill in premature ovarian failure: a randomized controlled trial of the effects on bone mineral density. J Clin Endocrinol Metab. 2016;101(9):3497-505.
114. Kou M-J et al. Traditional chinese medicine combined with hormone therapy to treat premature ovarian failure: a meta-analysis of randomized controlled trials. Afr J Tradit Complement Altern Med. 2016;13(5):160-9.

115. Kalantaridou SN, et al. Impaired endothelial function in young women with premature ovarian failure: normalization with hormone therapy. J Clin Endocrinol Metab. 2004:89(8):3907-13.

116. Ho K, et al. Effects of sex and age on the 24-hour profile of growth hormone secretion in man: importance of endogenous estradiol concentrations. J Clin Endocrinol Metab. 1987;64(1):51-8.

117. Hartmann BW, et al. Effect of hormone replacement therapy on growth hormone stimulation in women with premature ovarian failure. Fertil Steril. 1997;68(1):103-7.

118. Rossouw JE, et al. Postmenopausal hormone therapy and risk of cardiovascular disease by age and years since menopause. JAMA. 2007;297(13):1465-77.

119. Byington RP, et al. Effect of estrogen plus progestin on progression of carotid atherosclerosis in postmenopausal women with heart disease: HERS B-mode substudy. Arterioscler Thromb Vasc Biol. 2002:22(10):1692-7.

120. Grady D, et al. Cardiovascular disease outcomes during 6.8 years of hormone therapy: Heart and Estrogen/progestin Replacement Study follow-up (HERS II). JAMA. 2002;288(1):49-57.

121. Hendrix SL, et al. Effects of conjugated equine estrogen on stroke in the Women's Health Initiative. Circulation. 2006:113(20):2425-34.

122. Ganz PA, Breast cancer risk: is postmenopausal hormone therapy ever safe? 2005, LWW.

123. Beral V, Collaborators MWS. Ovarian cancer and hormone replacement therapy in the Million Women Study. The Lancet. 2007;369(9574):1703-10.

124. Vanecek J, Klein DC. Melatonin inhibits gonadotropin-releasing hormone-induced elevation of intracellular Ca2 + in neonatal rat pituitary cells. Endocrinology. 1992;130(2):701-7.

125. Baltaci AK, et al. Opposite effects of zinc and melatonin on thyroid hormones in rats. Toxicology. 2004;195(1):69-75.

126. Yang $Y$, et al. Melatonin as potential targets for delaying ovarian aging Curr Drug Targets. 2019;20(1):16-28.

127. Lee SJ, et al. American Society of Clinical Oncology recommendations on fertility preservation in cancer patients. J Clin Oncol. 2006;24(18):2917-31.

128. Oriol B, et al. Systemic methotrexate to treat ectopic pregnancy does not affect ovarian reserve. Fertil Steril. 2008;90(5):1579-82.

129. Shan W, et al., Melatonin provides protection against cisplatin-induced ovarian damage and loss of fertility in mice. Reproductive BioMedicine Online. 2020

130. Burger HG. Androgen production in women. Fertil Steril. 2002;77:3-5.

131. Casson P, et al. Dehydroepiandrosterone supplementation augments ovarian stimulation in poor responders: a case series. Hum Reprod. 2000;15(10):2129-32.

132. Gleicher N, Barad DH. Dehydroepiandrosterone (DHEA) supplementation in diminished ovarian reserve (DOR). Reprod Biol Endocrinol. $2011 ; 9(1): 1-12$

133. Zhang Q, et al. Immunomodulatory effect of human amniotic epithelial cells on restoration of ovarian function in mice with autoimmune ovarian disease. Acta Biochim Biophys Sin. 2019;51(8):845-55.

134. Simon A, Laufer N. Repeated implantation failure: clinical approach. Fertil Steril. 2012;97(5):1039-43.

135. Pourakbari, R., et al., Cell therapy in female infertility-related diseases: emphasis on recurrent miscarriage and repeated implantation failure. Life Sci. 2020;258:118181.

136. Mohamed SA, et al. Human mesenchymal stem cells partially reverse infertility in chemotherapy-induced ovarian failure. Reprod Sci. 2018;25(1):51-63.

137. Li H, et al. Human placenta-derived mesenchymal stem cells inhibit apoptosis of granulosa cells induced by IRE1 a pathway in autoimmune POF mice. Cell Biol Int. 2019:43(8):899-909.

138. Zhang $C$, The roles of different stem cells on premature ovarian failure. Curr Stem Cell Res Therapy, 2019.

139. Edessy $M$, et al. Autologous stem cells therapy, the first baby of idiopathic premature ovarian failure. Acta Med Int. 2016;3(1):19. 
140. Huang B, et al. Fetal liver mesenchymal stem cells restore ovarian function in premature ovarian insufficiency by targeting MT1. Stem Cell Res Ther. 2019;10(1):1-12.

141. Xiao G, et al., Amniotic fluid stem cells prevent follicle atresia and rescue fertility of mice with. 2014

142. Liu M, et al. Small extracellular vesicles derived from embryonic stem cells restore ovarian function of premature ovarian failure through PI3K/AKT signaling pathway. Stem Cell Res Ther. 2020;11(1):3.

143. Augello A, Kurth TB, De Bari C. Mesenchymal stem cells: a perspective from in vitro cultures to in vivo migration and niches. Eur Cell Mater. 2010;20(121):e33.

144. Paduano F, et al. Adipose tissue as a strategic source of mesenchymal stem cells in bone regeneration: a topical review on the most promising craniomaxillofacial applications. Int J Mol Sci. 2017;18(10):2140.

145. Riekstina $U$, et al. Embryonic stem cell marker expression pattern in human mesenchymal stem cells derived from bone marrow, adipose tissue, heart and dermis. Stem Cell Rev Rep. 2009;5(4):378-86.

146. Wagner W, et al. Comparative characteristics of mesenchymal stem cells from human bone marrow, adipose tissue, and umbilical cord blood. Exp Hematol. 2005;33(11):1402-16.

147. $\mathrm{Xu} \mathrm{L}$, et al. Tissue source determines the differentiation potentials of mesenchymal stem cells: a comparative study of human mesenchymal stem cells from bone marrow and adipose tissue. Stem Cell Res Ther. 2017:8(1):1-11.

148. Sun $\mathrm{H}$, et al. In vitro and in vivo effects of rat kidney vascular endothelial cells on osteogenesis of rat bone marrow mesenchymal stem cells growing on polylactide-glycoli acid (PLGA) scaffolds. Biomed Eng Online. 2007;6(1):41.

149. Ding D-C, et al. Human umbilical cord mesenchymal stem cells: a new era for stem cell therapy. Cell Transpl. 2015;24(3):339-47.

150. Wang HS, et al. Mesenchymal stem cells in the Wharton's jelly of the human umbilical cord. Stem Cells. 2004;22(7):1330-7.

151. Sarugaser R, et al. Isolation, propagation, and characterization of human umbilical cord perivascular cells (HUCPVCs). In: Stem cells in regenerative medicine. Springer; 2009. p. 269-79.

152. Asgari HR, et al. Human Wharton's jelly-derived mesenchymal stem cells express oocyte developmental genes during co-culture with placental cells. Iran J Basic Med Sci. 2015;18(1):22.

153. Kadner A, et al. Human umbilical cord cells: a new cell source for cardiovascular tissue engineering. Ann Thorac Surg. 2002;74(4):1422-8.

154. Bongso A, Fong C-Y. The therapeutic potential, challenges and future clinical directions of stem cells from the Wharton's jelly of the human umbilical cord. Stem Cell Rev Rep. 2013;9(2):226-40.

155. Fong $C-Y$, et al. Human Wharton's jelly stem cells have unique transcriptome profiles compared to human embryonic stem cells and other mesenchymal stem cells. Stem Cell Rev Rep. 2011;7(1):1-16.

156. Karahuseyinoglu S, et al. Biology of stem cells in human umbilical cord stroma: in situ and in vitro surveys. Stem cells. 2007;25(2):319-31.

157. Wang $Z$, et al. Study of the reparative effects of menstrual-derived stem cells on premature ovarian failure in mice. Stem Cell Res Ther. 2017;8(1):1-14.

158. Sdrimas K, Kourembanas S. MSC microvesicles for the treatment of lung disease: a new paradigm for cell-free therapy. Antioxid Redox Signal. 2014;21(13):1905-15.

159. Phinney DG, Pittenger MF. Concise review: MSC-derived exosomes for cell-free therapy. Stem cells. 2017;35(4):851-8.

160. Pawitan, J.A., Prospect of stem cell conditioned medium in regenerative medicine. BioMed Res Int. 2014;2014

161. Mohr A, Zwacka R. The future of mesenchymal stem cell-based therapeutic approaches for cancer-from cells to ghosts. Cancer Lett. 2018:414:239-49.

162. Hong $L$, et al. Protective effects of human umbilical cord mesenchymal stem cell-derived conditioned medium on ovarian damage. J Mol Cell Biol. 2020;12(5):372-85.

163. Eftekhar M, Naghshineh $E$, Khani P. Role of granulocyte colony-stimulating factor in human reproduction. J Res Med Sci. 2018;2018:23.

164. Akdemir A, et al. Granulocyte-colony stimulating factor decreases the extent of ovarian damage caused by cisplatin in an experimental rat model. J Gynecol Oncol. 2014;25(4):328
165. Wang $\mathrm{H}$, et al. Exogenous granulocyte-macrophage colony-stimulating factor promotes follicular development in the newborn rat in vivo. Hum Reprod. 2005;20(10):2749-56.

166. Qiu P, et al. Gender depended potentiality of differentiation of human umbilical cord mesenchymal stem cells into oocyte-Like cells in vitro. Cell Biochem Funct. 2013;31(5):365-73.

167. Huang $P$, et al. Differentiation of human umbilical cord Wharton's jelly-derived mesenchymal stem cells into germ-like cells in vitro. J Cell Biochem. 2010;109(4):747-54.

168. Yang $X$, et al. Mesenchymal stem cells derived from Wharton jelly of the human umbilical cord ameliorate damage to human endometrial stromal cells. Fertil Steril. 2011;96(4):1029-1036e4.

169. Zhu SF, et al. Human umbilical cord mesenchymal stem cell transplantation restores damaged ovaries. J Cell Mol Med. 2015;19(9):2108-17.

170. Mohamed SA, et al. Umbilical cord blood mesenchymal stem cells as an infertility treatment for chemotherapy induced premature ovarian insufficiency. Biomedicines. 2019;7(1):7.

171. Yang Y, et al. Transplantation of umbilical cord-derived mesenchymal stem cells on a collagen scaffold improves ovarian function in a premature ovarian failure model of mice. Vitro Cell Dev Biol Anim. 2019;55(4):302-11.

172. Wang $Z$, et al., Mesenchymal stem cell therapy using human umbilical cord in a rat model of autoimmune-induced premature ovarian failure. Stem Cells Int. 2020;2020.

173. Shen J. Dai Cao J-LS, Ability of human umbilical cord mesenchymal stem cells to repair chemotherapy-induced premature ovarian failure. World J Stem Cells. 2020;12(4):277.

174. Lu X, et al. The effects of human umbilical cord-derived mesenchymal stem cell transplantation on endometrial receptivity are associated with Th1/Th2 balance change and uNK cell expression of uterine in autoimmune premature ovarian failure mice. Stem Cell Res Ther. 2019;10(1):214

175. Song D, et al., Human umbilical cord mesenchymal stem cells therapy in cyclophosphamide-induced premature ovarian failure rat model. BioMed Res Int. 2016:2016.

176. Matsuzaki S, et al. HOXA-10 expression in the mid-secretory endometrium of infertile patients with either endometriosis, uterine fibromas or unexplained infertility. Hum Reprod. 2009:24(12):3180-7.

177. Achache H, Revel A. Endometrial receptivity markers, the journey to successful embryo implantation. Hum Reprod Update. 2006;12(6):731-46.

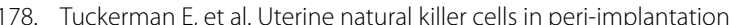
endometrium from women with repeated implantation failure after IVF. J Reprod Immunol. 2010;87(1-2):60-6.

179. Faas MM, De Vos P. Uterine NK cells and macrophages in pregnancy. Placenta. 2017:56:44-52.

180. Djurisic S, Skibsted L, Hviid TVF. A phenotypic analysis of regulatory T cells and uterine NK cells from first trimester pregnancies and associations with HLA-G. Am J Reprod Immunol. 2015;74(5):427-44.

181. Hwang S-S, et al. Differential expression of nuclear receptors in T helper cells. J Microbiol Biotechnol. 2009;19(2):208-14.

182. Eun Kwon H, Taylor HS. The role of HOX genes in human implantation. Ann N York Acad Sci. 2004:1034(1):1-18.

183. Kasteren VAN, Y.M., , et al. Incipient ovarian failure and premature ovarian failure show the same immunological profile. Am J Reprod Immunol. 2000;43(6):359-66.

184. Li J, et al. Treatment of autoimmune ovarian disease by co-administration with mouse zona pellucida protein 3 and DNA vaccine through induction of adaptive regulatory T cells. J Gene Med. 2008;10(7):810-20

185. Wang $P$, et al. Protective function of Bu Shen Huo Xue formula on the immunity of B6AF1 mice with experimental autoimmune premature ovarian failure. Exp Ther Med. 2018;15(4):3302-10.

186. Lu X, et al. The effects of human umbilical cord-derived mesenchyma stem cell transplantation on endometrial receptivity are associated with Th1/Th2 balance change and UNK cell expression of uterine in autoimmune premature ovarian failure mice. Stem Cell Res Ther. 2019;10(1):1-11.

187. Yin N, et al. Protective properties of heme oxygenase-1 expressed in umbilical cord mesenchymal stem cells help restore the ovarian function of premature ovarian failure mice through activating the JNK/BCl-2 
signal pathway-regulated autophagy and upregulating the circulating of CD8+ CD28- T cells. Stem Cell Res Ther. 2020;11(1):1-16.

188. Yang Z, et al. Therapeutic effects of human umbilical cord mesenchymal stem cell-derived microvesicles on premature ovarian insufficiency in mice. Stem Cell Res Ther. 2019;10(1):250.

189. Jalalie L, et al. Distribution of the CM-Dil-labeled human umbilical cord vein mesenchymal stem cells migrated to the cyclophosphamideinjured ovaries in C57BL/6 mice. Iran Biomed J. 2019;23(3):200.

190. Elfayomy AK, et al. Human umbilical cord blood-mesenchymal stem cells transplantation renovates the ovarian surface epithelium in a rat model of premature ovarian failure: possible direct and indirect effects. Tissue Cell. 2016;48(4):370-82.

191. Liu, Q., et al., The effects of human umbilical cord mesenchymal stem cell transplantation on female fertility preservation in mice. bioRxiv. 2020.
192. Lai D, et al. Human endometrial mesenchymal stem cells restore ovarian function through improving the renewal of germline stem cells in a mouse model of premature ovarian failure. J Transl Med. 2015;13(1):155.

193. Ding L, et al. Transplantation of UC-MSCs on collagen scaffold activates follicles in dormant ovaries of POF patients with long history of infertility. Science China Life Sciences. 2018;61(12):1554-65.

\section{Publisher's Note}

Springer Nature remains neutral with regard to jurisdictional claims in published maps and institutional affiliations.
Ready to submit your research? Choose BMC and benefit from:

- fast, convenient online submission

- thorough peer review by experienced researchers in your field

- rapid publication on acceptance

- support for research data, including large and complex data types

- gold Open Access which fosters wider collaboration and increased citations

- maximum visibility for your research: over $100 \mathrm{M}$ website views per year

At BMC, research is always in progress.

Learn more biomedcentral.com/submissions 